\title{
Splenic lobe/segment dearterialization
}

\author{
M. Shafique • D. Ignjatovic
}

Received: 22 May 2012 / Accepted: 24 July 2012/Published online: 31 August 2012

(C) Springer-Verlag 2012

\section{Dear Sir,}

Dr's Larkin, Carroll, McCormick, and Mehigan present an interesting technique for the control of a bleeding spleen [1]. This technique has in fact been previously published as a lobe or segment dearterialization technique for the control of a bleeding spleen during left hemicolectomy in open surgery [2]. The use of this technique through a minimally invasive access is innovative.

Another difference in this technique can be noticed at a glance. An endoscopic, reloadable, linear stapling device cannot distinguish between the branches of the splenic artery and divide only the most inferior segmental branches without dividing the veins as well. Blind use of stapling instruments within the splenic hilus could be considered hazardous by some surgeons since partial or complete stapling of the splenic vein could lead to further serious complications. As the authors take care to point out, one should wait and confirm a clear demarcation line prior to closing the abdomen.

Conflict of interest None.

\section{References}

1. Larkin JO, Carroll PA, McCormick PH, Mehigan BJ (2012) Control of splenic bleeding during splenic flexure mobilisation by devascularisation of the inferior pole of the spleen. Tech Coloproctol. doi:10.1007/s10151-012-0840-7

2. Ignjatovic D, Djuric B, Zivanovic V (2001) Is splenic lobe/ segment dearterialization feasible for inferior pole trauma during left hemicolectomy? Tech Coloproctol 5:23-25 